* Doutora em Direito pela Pontifica Universidade Católica de Minas Gerais (PUC-MG). Coordenadora do Núcleo de Pesquisa da Faculdade Milton Campos (FAMC). Professora do Mestrado em Relações Econômicas e Sociais da Faculdade Milton Campos (FAMC). Professora da linha Estado Democrático e Gestão de Redes da Faculdade de Políticas Públicas da Universidade do Estado de Minas Gerais (FAPEMIG). Pesquisadora FAPEMIG e CNPq. E-mail: dralucianacsouza@gmail.com

* Mestranda em Direito pela Faculdade Milton Campos (FAMC). Advogada. E-mail: fabiolafmattos@hotmail.com

\section{Controle De Integridade De Ações Públicas Durante A Pandemia De Covid-19}

\author{
Public Action Compliance During The Covid-19 \\ PANDEMIC
}

\section{Luciana Cristina de Souza* Fabiola Fonseca Fragas de Almeida*}

Como citar: SOUZA, Luciana Cristina; ALMEIDA, Fabiola Fonseca Fragas de. Controle de integridade de ações públicas durante a pandemia de COVID-19. Scientia Iuris, Londrina, v. 25, n. 1, p. 10-28, mar. 2021. DOI: 10.5433/21788189.2021v25n1p10. ISSN: $2178-8189$.

Resumo: A corrupção representa uma preocupação global, sendo que o contexto nacional também revela uma necessidade de aprimoramento constante dos instrumentos utilizados na luta contra esse mal. O compliance anticorrupção, presente na Lei $\mathrm{n}^{\mathbf{o}}$ 12.846/13, desperta a importância de mudança de paradigma nas relações público-privadas, sobretudo por partir da perspectiva de autorregulação regulada. Contudo, o instituto vem sofrendo críticas e descrédito em razão dos recorrentes escândalos de corrupção, sobretudo diante das oportunidades de fraude trazidas pela pandemia de COVID-19. A partir do pensamento de Jürgen Habermas sobre ética, este artigo, utilizando o método de abordagem dedutivo, através de procedimento bibliográfico e documental, visa contribuir para uma abordagem jurídicosociológica do instituto do compliance anticorrupção no cenário brasileiro, a fim de conferir-lhe maior efetividade na disseminação da cultura de integridade. Como resultado, constatou-se que a implementação dos programas de integridade pautada em um agir estratégico latente anula o seu caráter preventivo, sendo necessário desenvolver os pilares do compliance em um ambiente de confiança e transparência, que permita a participação de todos os envolvidos, atingindo, assim, a cooperação mútua no controle da corrupção.

Palavras-chave: Controle de integridade. Coronavírus. Corrupção. Ética. Gestão pública.

Abstract: Corruption is a global concern, and in Brazil there is a need for constant improvement of the instruments used to fight this evil. Anti-corruption compliance, present in Law 12.846/13, 
awakens the importance of a paradigm shift in public-private relations, especially from the perspective of regulated self-regulation. However, the institute has been criticized and discredited due to the recurrent corruption scandals, especially given the opportunities for fraud brought by the Covid-19 pandemic. Utilizing Jürgen Habermas approach on ethics, this article, using the deductive method, with bibliographic and documentary analysis, aims to contribute to a legal-sociological approach of anti-corruption compliance in Brazil, to give it greater effectiveness in disseminating the culture of integrity. As a result, this paper finds that the implementation of compliance programs based on latent strategic action cancels out their preventive nature, which is counterproductive to the development of compliance pillars in an environment of trust and transparency, which permits the participation of all those involved, reaching thus, cooperation in the control of corruption.

Keywords: Compliance. Coronavirus. Corruption. Ethics. Public management. 


\section{INTRODUÇÃO}

A corrupção, por ser um fenômeno social, mutável em razão do tempo e do espaço, demanda um conjunto de mecanismos de enfrentamento igualmente dinâmico, capaz de ser reformulado e aprimorado constantemente. Com a finalidade de efetivar uma autorregulação regulada no âmbito anticorrupção, surge o compliance, como uma promessa de criar um ambiente organizacional ético. Mais de meia década se passou desde a previsão expressa do mecanismo de integridade na Lei Anticorrupção brasileira, que conferiu enorme publicidade ao instituto, já bastante conhecido no cenário internacional. Contudo, revela-se no Brasil um cenário de desesperança com o compliance, na medida em que pessoas jurídicas empresárias praticam atos ilícitos que configuram corrupção mesmo após a adoção dos mecanismos de integridade, além dos índices preocupantes em pesquisas sobre o tema.

Trata-se de instituto cujo princípio norteador é a integridade, a qual deveria ser mantida em qualquer contexto. No entanto, verifica-se que diante do alargamento de oportunidades, o princípio é prontamente deixado de lado, dando lugar ao fenômeno da corrupção. Em 11 de março de 2020, a Organização Mundial da Saúde (OMS) decretou situação de pandemia de Covid-19, causada pelo novo coronavírus (WATANABE, 2020). Diante da rápida propagação do vírus e do aumento no índice de letalidade, surgiu a necessidade de compras de respiradores, construção de hospitais de campanha, criação de novos leitos de unidade de tratamento intensivo (UTI), de forma emergencial. O cenário se mostrou terreno fértil para a corrupção, através de obras e suprimentos superfaturados, não deixando resquício da tão falada integridade pública e privada.

Diante dessa perspectiva, surgem os seguintes questionamentos: por que o índice de corrupção, no Brasil, não diminuiu diante da publicidade dada ao compliance através da Lei $\mathrm{n}^{0} 12.846 / 13$ ? Por que os casos de corrupção estão ocorrendo mesmo diante de uma situação emergencial, que exige uma postura ainda mais íntegra dos envolvidos na interação públicoprivada? Levanta-se a hipótese de que o descrédito do compliance, enquanto mecanismo preventivo à corrupção, deriva de sua adoção a partir de um agir estratégico das pessoas jurídicas de direito privado sujeitas à Lei ${ }^{\circ} 12.846 / 13$. Logo, a observância e aplicação do pensamento de Jürgen Habermas acerca da construção da ética, pautada em um agir comunicativo, poderia conferir maior efetividade ao compliance, na criação de um ambiente de cooperação em prol do controle da corrupção.

O tema é atual e relevante, considerando o contexto atual em que o uso eficiente dos recursos públicos é crucial para que o Estado esteja preparado para lidar não só com a doença em situação de pandemia, mas também com os resultados que recairão na economia e demais áreas sensíveis da sociedade, o que exige uma atuação ética dos governantes e empresários nas contratações públicas. Para tanto, o presente trabalho utiliza o método de abordagem dedutivo, através de procedimento bibliográfico e documental, por meio de revisão de literatura sobre o tema e coleta de dados indiretos (SOUZA, 2020), com o objetivo de contribuir para uma abordagem jurídico-sociológica do instituto do compliance anticorrupção no cenário brasileiro, a fim de 
conferir-lhe maior efetividade na disseminação da cultura de integridade.

\section{PANORAMA ATUAL}

O conceito de corrupção é multifacetado, não só em razão das diversas óticas pelas quais o fenômeno pode ser analisado, mas por sofrer influências socioculturais, razão pela qual não parece haver tanta utilidade em tecer críticas à lista de conceitos cunhados à corrupção (VORSTER, 2013, p.2). A conotação pejorativa do termo parece certeira (FERREIRA FILHO, 1991, p. 2), embora haja teorias que tentam conferir-lhe efeitos positivos (HUNTINGTON, 2006; LEFF, 1964; LEYS, 1965). No presente estudo, adota-se o conceito de Carl Friedrich (2005, p. 15 apud WANIS, 2019, p. 27-28), concebido sob o viés histórico-sociológico:

[...] corrupção se caracteriza quando um agente detentor de poder, encarregado de certas funções, é levado, em troca de recompensas econômicas ou de outro tipo, a praticar atos em favor de quem provê a recompensa, os quais lesam o interesse do grupo ou da organização à qual o agente pertence, mais especificamente o governo.

O controle da corrupção representa uma preocupação mundial, sobretudo diante da globalização dos mercados, afinal o fenômeno é nocivo tanto à concorrência leal quanto à boa governança estatal, não havendo mais lugar para aceitar irregularidades ao subterfúgio de heranças culturais, como o famoso "jeitinho brasileiro" (FURTADO, 2015, p. 17-18).

A transnacionalidade do ilícito de corrupção levou à necessidade de cooperação entre os países, resultando em diversos documentos internacionais sobre o tema, como a Convenção Interamericana contra a Corrupção, aprovada no âmbito da Organização dos Estados Americanos (OEA), em 1996; a Convenção sobre o Combate da Corrupção de Funcionários Públicos Estrangeiros em Transações Comerciais Internacionais da Organização para Cooperação e Desenvolvimento Econômico (OCDE), aprovada em 1997; e a Convenção das Nações unidas contra a Corrupção, aprovada em 2003. Essas convenções internacionais foram assinadas também pelo Brasil, sendo que ingressaram no ordenamento jurídico pátrio através do Decreto $n^{\circ} 4.410 / 2002$, Decreto $n^{\circ}$ 3.678/2000 e Decreto $n^{\circ} 5.687 / 2006$, respectivamente.

Em razão do compromisso assumido pelo Brasil no cenário internacional, juntamente com o clamor social das manifestações populares ocorridas em junho de $2013^{1}$, foi sancionada a Lei $\mathrm{n}^{\mathrm{o}} 12.846$, em $^{1}$ de agosto de 2013, conhecida como Lei Anticorrupção ou Lei da Empresa Limpa, que prevê a responsabilização administrativa e civil de pessoas jurídicas pela prática de atos ilícitos de corrupção. A partir desse momento, ganha notoriedade, no Brasil ${ }^{2}$, o instituto do compliance anticorrupção, previsto sob a nomenclatura de mecanismo de integridade, no artigo $7^{\circ}$, VIII, da Lei da Empresa Limpa (BRASIL, 2013). Embora a lei não crie a obrigação de a pessoa

1 Nomeadas pela mídia como Jornadas de Junho.

2 Necessário acentuar que a notoriedade do compliance no cenário internacional não é recente, tanto que nos Estados Unidos, o Foreing Corrupt Pratices Act (FCPA), de 1977, é o marco no desenvolvimento do instituto. 
jurídica de direito privado implementar o compliance, prevê o abrandamento das sanções em razão da sua existência no âmbito organizacional.

Posteriormente, a Lei $\mathrm{n}^{\mathrm{o}}$ 13.303, de 30 de junho de 2016, denominada Estatuto Jurídico das Estatais ou, simplesmente, Lei das Estatais, passou a exigir mecanismos de integridade das empresas públicas e sociedades de economia mistas. O prazo, previsto no artigo 91 da referida lei (BRASIL, 2016), para a adequação das empresas estatais às exigências do estatuto, expirou em 30 de junho de 2018. Outro marco normativo do compliance, no Brasil, é o Decreto $\mathrm{n}^{\circ}$ 9.203, de 22 de novembro de 2017, que instituiu a governança na administração púbica direta, autárquica e fundacional. O artigo 19 do decreto prevê a implementação de programa de integridade "com o objetivo de promover a adoção de medidas e ações institucionais destinadas à prevenção, à detecção, à punição e à remediação de fraudes e atos de corrupção" (BRASIL, 2017). Apesar dos esforços normativos para a criação de ambiente privado e público pautados na integridade, os índices de corrupção não retraíram.

Segundo a $15^{\mathrm{a}}$ EY Global Fraud Survey (EY, 2018), pesquisa realizada entre outubro de 2017 e fevereiro de 2018, através de entrevista com 2.550 executivos de 55 países e territórios, $96 \%$ dos entrevistados no Brasil afirmaram que práticas de suborno/corrupção ocorrem amplamente em negócios em seu país, mesmo diante da edição da Lei da Empresa Limpa e do aumento da fiscalização anticorrupção nos três anos anteriores ao momento da pesquisa.

No Índice de Percepção da Corrupção (IPC) 2019, o Brasil ocupa o $106^{\circ}$ lugar na lista de avaliação de 180 países e territórios. Trata-se do quinto recuo consecutivo na comparação anual. O Brasil apresentou 35 pontos, numa escala de 0 a 100, em que 0 representa o país percebido como altamente corrupto e 100 como país altamente íntegro. Considerando que a pontuação média dos países é de 43 pontos, o Brasil encontra-se significativamente abaixo da média. Ainda de acordo com o relatório da Transparência Internacional, a Odebrecht foi condenada na justiça por ter pago US\$ 1 bilhão em propinas ao longo dos últimos 15 (quinze) anos a agentes públicos brasileiros e estrangeiros. (TRANSPARÊNCIA INTERNACIONAL BRASIL, 2020a)

Além de causar danos à legitimidade política, desacelerar o crescimento do país, gerar desigualdades sociais, uma das principais implicações da corrupção é a ineficiência das licitações (ROSE-ACKERMAN, 2004). As contratações público-privadas passam a ser permeadas pelo desvio de valores públicos, gerando, inclusive, distorção na alocação de recursos e, consequentemente, afetando os direitos fundamentais dos cidadãos. Murray e Spalding (2015) chegam a defender a consagração do direito à um ambiente livre de corrupção no rol de direitos humanos.

A pandemia de COVID-19 consegue estabelecer com clareza a causalidade entre a corrupção e a falta de efetividade de direitos fundamentais, como vida e saúde. Escancara como a "diminuição sistemática do financiamento da saúde, o mau uso do dinheiro disponível no orçamento [...] e a falta de compromisso dos três poderes com a vida da população, corroídos pela, incompetência e desumanidade, são facetas da mistanásia ${ }^{33 " ~(c o r r u p c ̧ a ̃ o ~ F E R R E I R A, ~ P O R T O, ~}$

3 Segundo Ferreira e Porto (2019), o termo mistanásia possui origem grega, significando morte infeliz, ou seja, "morte miserável, precoce e evitável. A esse respeito, Ferreira destaca que é a morte impingida pelos três níveis de governo por meio da manutenção da pobreza, da violência, das drogas, da falta de infraestrutura e de condições 
2019).

No Brasil, foi editada a Lei $\mathrm{n}^{\mathrm{o}} 13.979$, de 6 de fevereiro de 2020, que "dispõe sobre as medidas para enfrentamento da emergência de saúde pública de importância internacional decorrente do coronavírus responsável pelo surto de 2019" (BRASIL, 2020). O artigo $4^{\circ}$ da lei permite a dispensa do processo licitatório "para aquisição de bens, serviços, inclusive de engenharia, e insumos destinados ao enfrentamento da emergência de saúde pública de importância internacional decorrente do coronavírus." (BRASIL, 2020). Prevê, ainda, no $\S 3^{\circ}$ do referido dispositivo legal (BRASIL, 2020), a possibilidade, excepcional, de contratar com "empresas que estejam com inidoneidade declarada ou com o direito de participar de licitação ou contratar com o Poder Público suspenso, quando se tratar, comprovadamente, de única fornecedora do bem ou serviço a ser adquirido".

Considerando o Triângulo da Fraude, baseado na teoria de Donald Cressey (KASSEN; HIGSON, 2012, p. 192), que apresenta como primeira face a pressão/motivo, segunda face oportunidade e terceira face racionalização, verifica-se que a Lei ${ }^{\circ}$ 13.979/2020, juntamente com o crescimento da necessidade de agir estatal, de forma urgente, amplificou as oportunidades de fraude, o que tende a elevar o número de casos de corrupção.

Nesse sentido, diariamente, a mídia tem noticiado as operações deflagradas em razão de irregularidades na aplicação de valores públicos no combate à pandemia. O governo do Estado do Amazonas, por exemplo, comprou, com dispensa de licitação, 28 (vinte e oito) ventiladores pulmonares, pelo valor de R $2.900 .000,00$ (dois milhões e novecentos mil reais), de uma loja de vinhos, para o tratamento de pacientes infectados pelo novo coronavírus em estado grave (COSTA, 2020). Além de o valor unitário do produto estar exorbitantemente acima do valor de mercado, os respiradores foram considerados pelo Conselho Regional de Medicina do Amazonas (Cremam) como inadequados para a finalidade pretendida (COSTA, 2020).

No Estado de Santa Catarina, o Ministério Público estadual juntamente com o Tribunal de Contas do Estado e a Polícia Civil identificaram irregularidades na compra, mediante dispensa de licitação, de 220 (duzentos e vinte) ventiladores pulmonares, celebrada entre o governo de Santa Catarina e a empresa Veigamed, pelo valor de R $\$ 33.000 .000,00$ (trinta e três milhões de reais) (SC... 2020). O pagamento foi realizado de forma antecipada, contudo o prazo para entrega dos aparelhos expirou sem que estes fossem entregues ao governo estadual (SC..., 2020).

O Estado do Rio de Janeiro havia registrado 56.732 (cinquenta e seis mil setecentos e trinta e dois) casos confirmados de Covid-19 e 5.686 (cinco mil e seiscentas e oitenta e seis) mortes em razão da doença, até o dia 02 de junho de 2020 (RAMOS, 2020). Em meio a esse cenário, a Polícia Federal investiga, no referido estado, atos de corrupção em obras de hospitais de campanha para tratamento da doença (RAMOS, 2020).

No Estado de Roraima, foram comprados 30 (trinta) respiradores por R\$ 6.000.000,00 (seis milhões de reais), o que representa o valor unitário de $\mathrm{R} \$ 200.000,00$ (duzentos mil reais) (MELLO; GRILLO, 2020). O valor, além de muito acima do praticado no mercado, foi pago de 
forma antecipada, sendo que a contratada não entregou os aparelhos dentro do prazo e pediu a prorrogação por sessenta dias, razões pelas quais o Ministério Público de Contas pediu o bloqueio de bens e valores do ex-secretário de saúde responsável pela contratação e da pessoa jurídica contratada (MPC..., 2020).

Em razão da pandemia de Covid-19, a Transparência Internacional (2020b) realizou uma pesquisa na qual foram avaliados os portais de 26 governos estaduais, do Distrito Federal e de 26 capitais brasileiras, verificando a existência de informações sobre contratações emergenciais de forma fácileágil. No Ranking de Transparência em Contratações Emergenciais(TRANSPARÊNCIA INTERNACIONAL BRASIL, 2020b), em que foram listados os 26 Estados-membros e o Distrito Federal, os Estados acima mencionados ocupam as seguintes posições: $8^{\mathrm{a}}$ - Santa Catarina; $10^{\mathrm{a}}-$ Amazonas; $23^{\text {a }}$ - Rio de Janeiro; e $27^{\text {a }}$ - Roraima. Enquanto as quatro unidades da federação que receberam conceito ótimo em transparência nesse Ranking, ocupando os primeiros lugares foram Espírito Santo, Distrito Federal, Goiás e Paraná, nessa ordem.

Verifica-se, portanto, a ineficiência na relação entre Estado e particular reflete a existência de "solo propício para atos eivados de corrupção" (CEREN; CARMO, 2019, p. 90), assim como percebe-se a importância e nítida correlação do índice de transparência enquanto red flag de irregularidades. Dessa forma, a transparência da gestão pública e a existência de mecanismos de controle social são apontados, dentre outros, como fatores que permitem detectar ilícitos (YAZIGI, 1996, p. 106). Constata-se, ainda, que para haver a disseminação verdadeira da cultura de integridade, proposta como forma de prevenir a corrupção, não basta a previsão normativa incentivando ou exigindo a adoção de programas de compliance nas organizações.

\section{INTEGRIDADE E ÉTICA COMO FUNDAMENTOS NECESSÁRIOS}

Nos programas de compliance destaca-se o caráter preventivo, buscando evitar a prática do ilícito. Conforme Jesús-María Silva Sánchez (2013, p. 100 apud LUZ, 2018), a vigilância se dá através de mecanismos de autorregulação que visam "neutralizar fatores culturais ou dinâmicas de grupo favorecedoras de ilícitos" e "incentivar culturas de grupo favorecedoras de fidelidade ao direito". Atualmente, o instituto é aplicado em diversas áreas da gestão empresarial (fiscal, ambiental, trabalhista etc.), porém o presente trabalho tem como ponto central o mecanismo de integridade anticorrupção, previsto no artigo $7^{\circ}$, inciso VIII, da Lei $n^{\circ}$ 12.846/13.

Frequentemente, o compliance é relacionado às auditorias internas, como se fosse apenas uma nova terminologia, um neologismo estrangeiro, sendo possível que esse julgamento errôneo do instituto seja consequência da simples adoção protocolar do mecanismo (ALMEIDA; SAMPAIO JUNIOR, 2019, p. 38). Afinal, além de se diferenciar pelo caráter preventivo, o programa de integridade possui a finalidade de fomentar um novo padrão de mercado, pautado na ética (SILVEIRA; SAAD-DINIZ, 2015, p. 321).

Críticas são feitas à Lei Anticorrupção por esta pretender formalizar a relação públicoprivada com o discurso de compliance, o que consistiria numa farsa, porque não haveria boa prática que seria capaz de impedir atividades desonestas (SILVEIRA; JORGE, 2019, p. 134). Contudo, 
imprescindível compreender que a evolução da sociedade nos dirige a um novo paradigma, em que a ética deve reger as relações sociais de forma global, tanto para fins públicos quanto para fins privados (BARRILARI, 2018, p. 20). Fernando Galvão (2020, p. 161), ao escrever sobre a "sinceridade na instituição de medidas preventivas" na seara empresarial, relata:

A crítica que é dirigida aos programas de integridade denuncia que a implantação de tais programas se apresenta como reação natural de um segmento que não era tocado pelo sistema de repressão penal e utiliza do programa como um mecanismo defensivo para blindar a empresa ou, ao menos, reduzir os riscos de sua responsabilização. [...] O exame das críticas revela que o maior problema dos programas de integridade, na atualidade, é a sua carência de credibilidade.

A publicidade em torno do compliance, com a finalidade de convencer dos benefícios de sua implantação, tem desvirtuado a cultura de integridade por ele proposta, ao incentivar ações voltadas para o sucesso egocêntrico (organizacional ou pessoal) em driblar o sistema punitivo anticorrupção ou elevar os lucros através de uma economia reputacional. Conforme pontuam Ceren e Carmo (2019, p. 102):

[...] aquele que segue pura e simplesmente as normas do compliance, não necessariamente previne a corrupção. A pessoa jurídica que tem boas práticas não é aquela que segue o ordenamento como the convém (aproveitando-se de brechas), ou para ganhar um benefício direto, mas sim as que praticam tal como se desejassem praticar suas atividades empresariais de forma honesta, ou seja, sem margem pra condutas dúbias. Praticar apenas a formalidade legal, sem assimilar o espírito da ética, não diminuirá a corrupção, pelo contrário, trará apenas uma camuflagem uma aparência de legalidade.

Consta-se, portanto, um desvirtuamento dos mecanismos de integridade, tomados por um agir estratégico latente com finalidade de atingir um sucesso egocêntrico, o que faz com que o impacto preventivo do instituto seja anulado, não havendo diminuição nos índices de corrupção e dando lugar a novos casos de irregularidades nas contratações público-privadas, principalmente em situações de crise com o alargamento de oportunidades de fraude, como a pandemia de COVID-19.

Conforme dito anteriormente, o próprio conceito de corrupção sofre alterações conforme o espaço e o tempo, por isso a ética construída a partir de uma ação comunicativa, pautada em um discurso transparente, tende a contribuir de forma mais eficaz do que um conteúdo posto decorrente de pretensões de poder, o que não significa que deva ocorrer a desregulamentação, mas sim que haja a participação de todos no aperfeiçoamento dos mecanismos anticorrupção. Evidenciando o valor das reflexões de Jürgen Habermas no campo jurídico, Lima e Kosop (2019, p. 18) enfatizam:

A teoria habermasiana não visualiza uma racionalidade instrumental da ação controlada pelo subsistema jurídico das instituições constitucionais, mas procura nas ações materializadas no mundo da vida, uma comunicação intersubjetiva e um sentido racional que promova a integração necessária para orientar a vida particular e efetivar o ordenamento jurídico na esfera pública. 
Habermas (1979, p. 9-10) entende como bem-vinda a interdisciplinariedade (extrapolamento da filosofia), a qual "permite focalizar uma faceta pluralista da teoria do agir comunicativo", afirmando, inclusive, que "as proposições fundamentais da teoria do agir comunicativo ramificam-se em diferentes universos de discurso e contextos de argumentação nos quais elas têm que comprovar-se". Dessa forma, como a corrupção desconsidera o Estado de Direito e enfraquece a democracia, a utilização da teoria do agir comunicativo, de forma interdisciplinar, para potencializar os efeitos positivos do compliance parece ser um bom caminho.

A ação instrumental consiste no agir com a finalidade de manipular o mundo natural, relacionada por Habermas (1979, p. 40), à habilidade humana de trabalhar, somente se revelando como um problema quando é aplicada no meio social enquanto ação estratégica. Weber, importante fonte para as reflexões de Habermas, embora reconhecesse que a racionalidade instrumental não era a única forma que o raciocínio pudesse tomar, já apontava que a razão instrumental estava se tornando cada vez mais dominante na cultura capitalista, inclusive nas burocracias governamentais e comerciais (HABERMAS, 1984, p. 143-271). Não se pretende que as organizações deixem de lado a ação instrumental necessária às atividades cotidianas, mas a construção de uma cultura de integridade não é resultado de um agir estratégico de transparecer ética em prol de economia reputacional, para atenuar sanções ou cumprir exigência legal.

A Lei Anticorrupção abre espaços de interação comunicativa entre o setor privado e o setor público, apresentando instrumentos de alinhamento consensual de conduta, não só através do compliance, como será demonstrado adiante, como também por meio do acordo de leniência. A fiscalização tradicional através de uma heterorregulação estatal mostrou-se insuficiente para o controle de fraudes na relação público-privada, emergindo a tônica da cooperação mútua, numa perspectiva de autorregulamentação regulada (responsive regulation), o que deve ser feito através de uma ética construída, pautada em um discurso transparente. Embora a concepção de consensualidade e cooperação no combate à corrupção possa causar estranheza ${ }^{4}$, demonstra uma faceta da resiliência estatal (SOUZA, 2015) ao adotar uma postura não adversarial e propiciar uma postura proativa do cidadão corporativo, ou seja, seria o Estado se flexibilizando frente a novas demandas sociais, porém mantendo sua essência estrutural.

A dinâmica existente na interação entre sociedade, empresa e Estado resulta numa tensão, consequência das diferentes lógicas de cada sistema, consequentemente, o compliance surge na busca de se encontrar um caminho de integração, que faça com que possa haver "coexistência da força do mercado, da tutela regulamentar do Estado e de uma sociedade civil mais harmônica e igualitária.” (BARRILARI, 2018, p. 19-20). O compliance anticorrupção, na forma como apresentado pela Lei $n^{\circ}$ 12.846/2013, parece buscar interação consensual entre o Poder Público e o ente privado, tanto que não houve a obrigatoriedade em sua adoção, assim como não houve

4 Talvez a ideia de integração dos setores público e privado no combate à corrupção não pareça tão utópico se considerarmos que o Foreign Corrupt Pratices Act-FCPA, em 1977 nos Estados Unidos, foi fruto de um movimento do setor empresarial em busca de um ambiente de concorrência leal (level playing fiel), após escândalos de corrupção envolvendo contratos da empresa Lockeed Aircraft Corporation com diversos países (NASCIMENTO, 2019, p. 240). 
a delimitação de um critério temporal para a concessão do benefício vinculado à existência do compliance. Reflete a ideia de mudança de paradigma, visando valorizar aquela organização que buscou alterar a cultura empresarial enfatizando a ética e a integridade.

O legislador não fixou "o marco [temporal] que encaixará as empresas que mantém um comportamento ético, das que não seguem tal raciocínio, mas aderem apenas para benefício próprio e malefício da coletividade, e do próprio instituto do compliance." (CEREN; CARMO, 2019 , p. 89). Assim, em tese, seriam beneficiadas pela diminuição da pena tanto a organização que sofreu uma falha no compliance por motivos alheios à sua atuação, quanto a organização que somente adotou o programa de integridade após a abertura do procedimento de responsabilização por prática de ato ilícito de corrupção. Contudo, conforme pontua Galvão (2020, p. 173), "um programa 'maquiagem' de integridade" não faz com que o ente privado tenha direito a uma redução na sanção, através da combinação do artigo $7^{\circ}$, VIII e parágrafo único, da Lei ${ }^{\circ}$ 12.846/2013 com o artigo 18, inciso V, e artigo 42 do Decreto 8.420/15. O autor (GALVÃO, 2020, p. 170171) acrescenta, ainda, que o compliance implantado apenas para dificultar a responsabilização da pessoa jurídica configura causa de aumento da sanção, com base no artigo 17 , II, do Decreto $\mathrm{n}^{\circ}$ $8.420 / 15$.

A cooperação mútua é traço marcante na ideia de compliance, servindo de referencial para a atuação de todos os stakeholders da organização, em sintonia com a performance desta no mercado em que atua (SILVEIRA; JORGE, 2019). Imprescindível um discurso ético para sua efetivação, tanto no ambiente interno para a construção e concretização do princípio vetor da integridade, quanto externo, para melhor interação entre entes públicos e privados, bem como para que todos que de alguma forma se relacionam com o ente privado tenham clareza dos valores por ele adotados (afinal, a responsabilização por atos ilícitos de corrupção podem decorrer de atos de terceiros). Para tanto, o discurso interno e externo deve ter pretensões de validade, inteligibilidade, verdade e sinceridade, gerando um ambiente marcado pela confiança.

Nas empresas, assim como no Estado, quando eclodem os atos de corrupção, verificase a existência de funcionários honestos que são atraídos por seu empregador para um nexo de práticas corruptas, porém não se sentem individualmente responsáveis (VORSTER, 2013, p. 2). A tendência de simplificar sugere que os traços da personalidade da pessoa são fundamentais para prever o comportamento (ético ou antiético), contudo, ao analisar uma conduta antiética é necessário considerar a cultura organizacional mais ampla, tendo em vista que o ambiente em que se contextualiza a ação é fator fundamental de impacto, podendo, inclusive, anular a influência da personalidade (CHEREPANOVA, 2019). A implantação de programas de compliance podem passar a imagem de que a organização se preocupa com a ética, porém, esta pode não ser a realidade, induzindo erroneamente as atitudes de stakeholders. Revela-se, dessa forma, que a razão instrumental não está presente somente na relação entre pessoa jurídica empresária e Estado, mas permeia as demais relações da organização, como empregado-empregador. Daí resulta a indispensabilidade do comprometimento e apoio da alta direção, chamado de tone at the top, como um dos pilares do compliance (CGU, 2015). 
Além do comprometimento da alta direção, o Manual da Controladoria Geral da União (CGU, 2015), contendo diretrizes do programa de integridade para empresas privadas, elenca outros pilares do Compliance: independência e autonomia da instância responsável pelo programa de integridade; análise de perfil e riscos; estruturação das regras e instrumentos (incluindo o treinamento e aplicação de medidas disciplinares); e estratégias de monitoramento contínuo. Tanto na verificação de riscos quanto no monitoramento e utilização de canais de denúncia, a eficiência perpassa por um ambiente de confiança, em que todos os envolvidos com a organização sejam chamados a uma participação ativa e se sintam em uma situação de discurso ideal, em que, além da suposição de veracidade dos participantes, tem-se como pressuposto que todos os legitimados estejam aptos a tomar parte na discussão.

Retomando a ideia de Bom Cidadão Corporativo, como sendo a pessoa jurídica empresária que cumpre com as normas jurídicas e também coopera, Silveira e Saad-Diniz trazem o conceito de bom governo nas palavras de Adán Nieto Martín:

[...] basicamente la ideia del buen gobierno es 'luchar' contra el abuso de poder dentro de las corporaciones, generando al igual que los sistemas democráticos, um sistema de checks and balances y herramientas de control del 'pueblo' - los shareholders y stakeholders - sobre los governantes administradores (NIETO MARTÍN, 2013, p. 24 apud SILVEIRA; SAAD-DINIZ, 2015, p. 71).

A partir de uma cooperação mútua, seja na relação entre stakeholder e organização ou organização e Estado, pautada em um processo de comunicação buscando o entendimento, as pretensões de validade também devem ser confrontadas pelos os critérios propostos por Habermas (1984): veracidade da afirmação; correção normativa; autenticidade e sinceridade. Assumindo, ainda, que as interpretações sofrem variações de acordo com os elementos do mundo da vida (social, cultural e individual). Isso é fundamental para assegurar um importante princípio, o da transparência. Segundo Habermas (1979, p. 13):

[...] convém ter em mente que os sujeitos jurídicos privados não podem chegar ao gozo das mesmas liberdades subjetivas, se eles mesmos - no exercício comum de sua autonomia política - não tiverem clareza sobre interesses e padrões justificados e não chegarem a um consenso sobre aspectos relevantes, sob os quais o que é igual deve ser tratado como igual e o que é diferente deve ser tratado como diferente.

Convergindo com o conceito de autorregulação regulada e o pilar do compliance de estruturação de regras, a ética, em Habermas, ao não se preocupar com orientações de conteúdo, permite uma construção que comporta uma contextualização e uma interação com o outro para atingir o consenso. Nesse ponto, a ação comunicativa abrange tanto a ação consensual, em que os pressupostos comuns são tomados como garantidos, quanto a ação orientada para chegar a um entendimento, em que se tenta estabelecer um solo comum (HABERMAS, 1979, p. 209). 
Estabelecido esse consenso, cada indivíduo dentro da organização atuará respeitando o que foi definido. Nesse sentido, Habermas escreve:

I shall speak of communicative action whenever the actions of the agents involved are coordinated not through egocentric calculations of success but through acts of reaching understanding. In communicative action participants are not primarily oriented to their own individual successes; they pursue their individual goals under the condition that they can harmonize their plans of action on the basis of common situation definitions. In this respect the negotiation of definitions of the situation is an essential element of the interpretive accomplishments required for communicative action. (HABERMAS, 1984, p. 285-286) ${ }^{5}$

Considerando que dirigir as ações pautadas no princípio da integridade significa agir "com inteireza de caráter", não duvidar do que é o correto a ser feito, ou seja, significa agir "realizando as funções esperadas, sempre de acordo com os mesmos padrões éticos, independentemente das circunstâncias, seja em um ambiente público ou em um ambiente estritamente privado" (ZENKNER, 2018, p. 90), o estabelecimento de um solo comum através do entendimento possibilita a efetividade do compliance ainda que em tempos de crise.

\section{IMPORTÂNCIA DO COMPLIANCE PARAA SUSTENTABILIDADE}

Como se expôs, atender a parâmetros de integridade, tanto na área pública quanto privada, consiste em adotar ações que preservem valores éticos e de transparência. Visando a ampliar as práticas éticas e de integridade, o Brasil assumiu importante compromisso perante a Organização das Nações Unidas. Um deles é com a meta 5, do Objetivo de Desenvolvimento Sustentável n. 16 (ODS 16): "Reduzir substancialmente a corrupção e o suborno em todas as suas formas." (ONU, 2015). Os dois indicadores têm sido aplicados para mensurar essa meta:

16.5.1 Proporção de pessoas que tiveram pelo menos um contato com um funcionário público e que o subornaram, ou foram demandadas a pagar suborno para esse funcionário durante os 12 meses anteriores (Tier II).

16.5.2 Proporção de empresas que tiveram pelo menos um contato com um funcionário público e pagaram suborno ao oficial, ou foram demandadas a pagar suborno nos 12 meses anteriores (Tier II).

Isso se coaduna com a meta 16.6, voltada ao desenvolvimento de instituições eficazes, responsáveis e transparentes em todos os níveis. Exige, igualmente, um esforço do Estado brasileiro

5 Em tradução livre: "Devo falar ação comunicativa sempre que as ações dos agentes envolvidos forem coordenadas não através de cálculos egocêntricos de sucesso, mas através de atos para alcançar o entendimento. Na ação comunicativa, os participantes não são primariamente orientados para seus próprios sucessos individuais; eles perseguem seus objetivos individuais sob a condição de que possam harmonizar seus planos de ação com base em uma definição comum de situação. A este respeito, a negociação de definição da situação é um elemento essencial do complemento interpretativo necessário à ação comunicativa." 
voltado à obtenção de "recursos humanos, financeiros, tecnológicos e de governança (arranjo institucional e ferramentas: legislação, planos, políticas públicas, programas, etc.) necessários ao alcance dos ODS" (IPEA, 2018, p. 430). Sob a ótica pública, significa assegurar instrumentos concretos de monitoramento da integridade dos gestores públicos. Sob a perspectiva das empresas, a boa execução de medidas anticorrupção e de controle ético das relações econômicas entre essas e o poder público evitará que práticas ilegais e que prejudicam a sociedade brasileira continuem a ser frequentes, pois o prejuízo econômico de atos de corrupção (IPEA, 2018), muitas vezes, resulta no comprometimento de verbas destinadas a cumprir outras metas de sustentabilidade como as de saúde, vitais no atual cenário pandêmico.

A sustentabilidade corporativa, tanto pública quanto privada, deve ser um compromisso dos stakeholders e dos gestores públicos para assim cumprir o Pacto Global, em especial o Princípio 10: "As empresas devem trabalhar contra a corrupção em todas as suas formas, incluindo extorsão e suborno." (UNITED NATIONS, 2020, tradução nossa). De acordo com os dados recentemente publicados do The 2019 Global Business Ethics Survey, publicado pelo grupo Internacional Ethics \& Compliance Initiative (2020, p. 9, tradução nossa) nas organizações ao redor do mundo que foram pesquisadas se observou que "um elemento-chave da eficácia programas de ética e conformidade é até que ponto organizações incentivam, protegem e valorizam os relatórios preocupações e suspeita de irregularidades"

Esse relatório avaliou as condições em que são estabelecidas as relações entre empregados e seus líderes nas organizações. Infere-se que, para garantir um modelo de desenvolvimento sustentável humano e economicamente, também metas da Agenda 2030, o ambiente das empresas deve assegurar a integridade. Sem uma comunicação adequada entre empregados e sua liderança, as práticas de corrupção não serão combatidas. Muitas vezes, por medo de se fazer uma denúncia porque o ambiente corporativo não favorece a conduta ética. Se tais corporações vierem a negociar com o Estado, esse perfil de comportamento será levado para as relações com o Poder Público e prejudicará a consecução do interesse comum dos cidadãos que esperam da Administração Pública uma postura de probidade.

O comprometimento da alta direção com padrões nacionais e internacionais de ética deve ser central no combate à corrupção, em especial na atualidade porque as demandas na área de saúde são de grande monta e as desigualdades sociais tornam a situação de alguns grupos da sociedade ainda mais vulnerável, seja porque não podem usufruir do isolamento social e do teletrabalho, ou em razão da dificuldade de acesso a tratamentos de saúde gratuitos em tempo hábil para preservação da vida. A questão da sustentabilidade é primordial porque não se refere apenas ao crescimento econômico, todavia, busca assegurar a dignidade da vida humana e o desenvolvimento pleno de todos os cidadãos, como proposto por Mahbub U1 Haq e Amartya Sen ao criarem o Índice de Desenvolvimento Humano (PNUD, 2020).

A continuidade das relações sociais e econômicas no cenário do COVID-19 nos força a reestruturar o modo de organização do Estado, de relações entre esse e empresas, de execução e prioridade para políticas públicas. Cada decisão é crucial para definir sobre a qualidade de vida 
humana, sobre o acesso a recursos de sobrevivência e de direito à saúde, para resgatar os valores humanos no ambiente de trabalho, etc. A ética financeira sempre foi necessária e a corrupção de seus valores de integridade uma ofensa à legislação; no entanto, hoje ela pode interferir drasticamente no acesso a recursos para preservação da vida humana por causa da insegurança econômica que um modelo de desenvolvimento sem preocupação com as pessoas e com a ética pode ocasionar (SEN, 1999). Mais do que nunca o compliance deve ser implantado e exigido de todos os stakeholders e da própria autoridade pública.

\section{CONCLUSÃO}

A produção de uma norma jurídica, por si só, não tem o condão de alterar a realidade, logo não se poderia esperar que a previsão normativa do compliance fosse o suficiente para modificar a ética empresarial. Contudo, a publicidade realizada em torno do mecanismo, como promessa de evitar sanções e, ainda, promover lucro a partir de uma economia reputacional, dificultou a construção de uma cultura de integridade. Da mesma forma, a mera implementação dos programas de compliance por uma organização não atende ao apelo preventivo do mecanismo. Detectou-se, assim, que a adoção do compliance pautada em um agir estratégico latente, com finalidade de atingir um sucesso egocêntrico, faz com que o impacto preventivo do instituto seja anulado, o que responde aos questionamentos realizados no início deste estudo, confirmando a hipótese levantada.

A falta de sinceridade na adoção do compliance pelas organizações reflete direta e negativamente nas contratações público-privadas, sobretudo em momentos de crise, como na pandemia de Covid-19, em que as oportunidades de fraudes aumentam. Como a integridade, princípio norteador de um compliance efetivo, não está enraizada, não há clareza nos atores sociais quanto aos limites de sua atuação, dando lugar à atos de corrupção. O pensamento de Habermas sobre a ética construída a partir de um discurso transparente com pretensões de validez criticável foi utilizado, de forma interdisciplinar, a fim de possibilitar a concretização da cooperação mútua no compliance anticorrupção, ao contribuir com ambiente de discurso ideal, permeado por confiança e em que todos os legitimados são chamados a participar, seja na relação do ente privado com o Estado ou nas relações daquele com os stakeholders. Isso permite que o consenso seja alcançado respeitando os valores éticos nas relações sociais.

Considerando-se o cenário que a atual pandemia fez surgir, devem ser feitas severas reflexões sobre a sustentabilidade da vida humana e das condições econômicas em que essa se desenvolve. E a preocupação com a integridade se torna ainda mais vital, uma vez que as verbas desviadas poderão custar milhares de vidas.

\section{REFERÊNCIAS}

ALMEIDA, Fabíola Fonseca Fragas de; SAMPAIO JÚNIOR, Rodolpho Barreto. A necessária 
compreensão do compliance sob a perspectiva da ética aristotélica. In: MARTINS, Thiago Penido; MAGALHÃES, Rodrigo Almeida; SAMPAIO JÚNIOR, Rodolpho Barreto (org.). Judicialização e direitos fundamentais. Belo Horizonte: Editora D’Plácido, 2019. v. 5.

BARRILARI, Cláudia Cristina. Crime empresarial, autorregulação e compliance. São Paulo: Thomson Reuters Brasil, 2018.

BRASIL. Decreto no 9.203, de 22 de novembro de 2017. Dispõe sobre a política de governança da administração pública federal direta, autárquica e fundacional. Brasília, DF: Presidência da República, 2017. Disponível em: http://www.planalto.gov.br/ccivil_03/_ato2015-2018/2017/ decreto/D9203.htm. Acesso em: 5 jun. 2020.

BRASIL. Lei $\mathbf{n}^{\mathbf{0}} \mathbf{1 2 . 8 4 6}$, de $1^{\mathbf{0}}$ de agosto de 2013. Dispõe sobre a responsabilização administrativa e civil de pessoas jurídicas pela prática de atos contra a administração pública, nacional ou estrangeira, e dá outras providências. Brasília, DF: Presidência da República, 2013. Disponível em: http://www.planalto.gov.br/ccivil_03/_ato2011-2014/2013/lei/112846.htm. Acesso em: 3 jun. 2020.

BRASIL. Lei no 13.303, de 30 de junho de 2016. Dispõe sobre o estatuto jurídico da empresa pública, da sociedade de economia mista e de suas subsidiárias, no âmbito da União, dos Estados, do Distrito Federal e dos Municípios. Brasília, DF: Presidência da República, 2016. Disponível em: http://www.planalto.gov.br/ccivil_03/_ato2015-2018/2016/lei/113303.htm. Acesso em: 5 jun. 2020.

BRASIL. Lei $\mathbf{n}^{\mathbf{0}}$ 13.979, de 06 de fevereiro de 2020. Dispõe sobre as medidas para enfrentamento da emergência de saúde pública de importância internacional decorrente do coronavírus responsável pelo surto de 2019. Brasília, DF: Presidência da República, 2020. Disponível em: http://www.planalto.gov.br/ccivil_03/_ato2019-2022/2020/lei/L13979.htm. Acesso em: 9 jun. 2020.

CEREN, João Pedro; CARMO, Valter Moura do. Crítica ao compliance na lei brasileira anticorrupção. Revista do Direito Público, Londrina, v. 14, n. 3, p. 87-109, dez. 2019. DOI: 10.5433/24157-108104-1.2019v14n3p.87.

CGU - CONTROLADORIA GERAL DA UNIÃO. Programa de integridade: diretrizes para empresas privadas. Brasília, DF: CGU, 2015. Disponível em: https://www.gov.br/cgu/pt-br/ centrais-de-conteudo/publicacoes/integridade/arquivos/programa-de-integridade-diretrizes-paraempresas-privadas.pdf. Acesso em: 15 jun. 2020.

CHEREPANOVA, Vera. Who's to blame? The bad apple or the barrel? The FCPA Blog, [s. l.], 14 fev. 2019. Disponível em: https://fcpablog.com/2019/02/14/whos-to-blame-the-bad-apple-orthe-barrel/. Acesso em: 25 maio 2020.

COSTA, Flávio. AM compra respiradores 'inadequados' em loja de vinho e paga 316\% mais caro. UOL, São Paulo, 20 abr. 2020. Disponível em: https://noticias.uol.com.br/saude/ultimasnoticias/redacao/2020/04/20/amazonas-compra-de-adega-respiradores-inadequados-com- 
sobrepreco-de-316.htm. Acesso em: 4 jun. 2020.

ETHICS \& COMPLIANCE INITIATIVE - ECI. The link between supervisor leadership and workplace behaviors. Viena: ECI, 2020. Disponível em: https://www.ethics.org/wp-content/ uploads/2019-Global-Business-Ethics-Survey-4.pdf. Acesso em: 17 jun. 2020.

EY- BUILDING A BETTER WORKING WORLD. Integrity in the spotlight: the future of compliance. 2018. Disponível em: https://assets.ey.com/content/dam/ey-sites/ey-com/en_gl/ topics/assurance/assurance-pdfs/ey-integrity-in-spotlight.pdf. Acesso em: 25 maio 2020.

FERREIRA FILHO, Manoel Gonçalves. A corrupção como fenômeno social e político. Revista de Direito Administrativo, Rio de Janeiro, v. 185, p. 1-18, jul./set. 1991. Disponível em: http:// bibliotecadigital.fgv.br/ojs/index.php/rda/article/view/44482/47693. Acesso em: 28 maio 2020.

FERREIRA, Sidnei; PORTO, Dora. Mistanásia x qualidade de vida. Revista Bioética, Brasília, v. 27, n. 2, abr./jun. 2019. Disponível em: http://revistabioetica.cfm.org.br/index.php/revista_ bioetica/article/view/2210. Acesso em: 4 jun. 2020.

FURTADO, Lucas Rocha. As raízes da corrupção no Brasil: estudos de caso e lições para o futuro. Belo Horizonte: Fórum, 2015.

GALVÃO, Fernando. Teoria do crime da pessoa jurídica: proposta de alteração do PLS n ${ }^{\circ}$ 236/12. Belo Horizonte: D’Plácido, 2020.

HABERMAS, Jürgen. Communication and the evolution of society. Boston, MA: Beacon Press, 1979.

HABERMAS, Jürgen. Direito e democracia: entre facticidade e validade. Tradução de Flávio Beno Siebeneichler. Rio de Janeiro: Tempo Brasileiro, 1997. v. 1.

HABERMAS, Jürgen. The theory of communicative action: reason and the rationalization of society. Tradução de Thomas McCarthy. Boston: Beacon Press, 1984. v.1.

HUNTINGTON, Samuel P. Political order in changing societies. London: Yale University Press, 2006.

IPEA -INSTITUTO DE PESQUISA ECONÔMICA APLICADA. Agenda 2030. Rio de Janeiro: IPEA, 2018. Disponível em: https://www.ipea.gov.br/portal/images/stories/PDFs/livros/ livros/180801_ods_metas_nac_dos_obj_de_desenv_susten_propos_de_adequa.pdf. Acesso em: 10 jun. 2020.

KASSEN, Rasha; HIGSON, Andrew. The new fraud triangle model. Journal of Emerging Trends in Economics and Management Sciences, South, n. 3, p. 191-195, 2012.

LEFF, Nathaniel H. Economic development through bureaucratic corruption. American 
Behavioral Scientist, Princeton, v. 8, n. 3, p. 8-14, 1 nov. 1964. Disponível em: https://journals. sagepub.com/doi/10.1177/000276426400800303. Acesso em: 4 jun. 2020.

LEYS, Colin. What is the problem about corruption? The Journal of Modern African Studies, Cambridge, v. 3, n. 2, Aug. 1965, p. 215-230. DOI 10.1017/S0022278X00023636.

LIMA, José Edmilson de Souza; KOSOP, Roberto José Covaia. O agir comunicativo inserido no consenso democrático: incursões do campo jurídico no contexto social a partir de Jurgen Habermas. Scientia Iuris, Londrina, v. 23, n. 2, p. 10-25, jul. 2019. DOI: 10.5433/2178-8189.2019v23n2p10. ISSN: 2178-8189.

LUZ, Ilana Martins. Compliance e omissão imprópria. Belo Horizonte: Editora D’Plácido, 2018.

MELLO, Bernardo; GRILLO, Marco. A pandemia como brecha para a corrupção no Brasil. Época, São Paulo, 15 maio 2020. Disponível em: https://epoca.globo.com/brasil/a-pandemiacomo-brecha-para-corrupcao-no-brasil-1-24427569. Acesso em: 04 jun. 2020.

MPC pede bloqueio de contas de ex-secretário e de donos de empresa. Folha BV, Boa Vista, 7 maio 2020. Disponível em: https://folhabv.com.br/noticia/CIDADES/Capital/MPC-pedebloqueio-de-contas-de-ex-secretario-e-de-donos-de-empresa/65322. Acesso em: 15 jun. 2020.

MURRAY, Mathew; SPALDING, Andrew. Freedom from oficial corruption as a human right. Brookings Institution, Washington, 28 jan. 2015. Disponível em: https:/www.brookings.edu/ research/freedom-from-official-corruption-as-a-human-right/. Acesso em: 5 jun. 2020.

NASCIMENTO, José Carlos Martins do. Compliance e legislação internacional. In: OLIVEIRA, Luís Gustavo Miranda de (org.). Compliance e integridade: aspectos práticos e teóricos. Belo Horizonte: Editora D’Plácido, 2019. p. 233-271.

ONU - ORGANIZAÇÃO DAS NAÇÕES UNIDAS. Agenda 2030. Brasília, DF: ONU Brasil, 2015. Disponível em: https://nacoesunidas.org/pos2015/. Acesso em: 10 jun. 2020.

PNUD - PROGRAMA DAS ÇÕES UNIDAS PARA O DESENVOLVIMENTO. O que é o IDH. Brasília: PNUD, 2020. Disponível em: https://www.br.undp.org/content/brazil/pt/home/idh0/ conceitos/o-que-e-o-idh.html. Acesso em: 10 jun. 2020.

RAMOS, Ana Paula. Coronavírus no RJ: falta de leitos, flexibilização de isolamento e suspeita de corrupção. Yahoo Notícias, [s. l.], 3 jun. 2020. Disponível em: https://br.noticias.yahoo.com/ coronavirus-rj-falta-leitos-flexibilizacao-isolamento-corrupcao-185101557.html. Acesso em: 4 jun. 2020.

ROSE-ACKERMAN, Susan. A economia política da corrupção. In: ELLIOT, Kimberly Ann (org.). A corrupção e a economia global. Brasília: UnB, 2002. p. 50-102.

SAAD-DINIZ, Eduardo. Ética negocial e compliance: entre a educação executiva e a interpretação judicial. São Paulo: Thomson Reuters Brasil, 2019. 
SC perde segundo secretário por suspeita de fraude em compra de respiradores. UOL, São Paulo, 11 maio 2020. Disponível em: https://noticias.uol.com.br/saude/ultimas-noticias/ redacao/2020/05/11/sc-perde-2-secretario-por-suspeita-de-fraude-em-compra-de-respiradores. htm. Acesso em: 4 jun. 2020.

SEN, Amartya. Desenvolvimento como liberdade. Tradução de Laura Teixeira Motta. São Paulo: Companhia de Bolso, 1999.

SILVEIRA, Daniel Barile; JORGE, Carlos Henrique Miranda. O compliance e seus reflexos no direito brasileiro. Scientia Iuris, Londrina, v. 23, n. 1, p. 125-143, mar. 2019. DOI: 10.5433/2178-8189.2019v23n1p125. ISSN: 2178-8189.

SILVEIRA, Renato de Mello Jorge; SAAD-DINIZ, Eduardo. Compliance, direito penal e lei anticorrupção. São Paulo: Saraiva, 2015.

SOUZA, Luciana C. Análise crítica da legitimidade do Estado a partir da aplicação do princípio da resiliência. In: CONGRESSO DO CONPEDI, 24., 2015, Belo Horizonte. Anais [...]. Belo Horizonte: Escola Superior Dom Helder Câmara, 2015.

SOUZA, Luciana C. Estrutura lógica de organização da pesquisa científica texto básico para auxiliar pesquisadores. Belo Horizonte, EdUEMG, 2020.

TRANSPARÊNCIA INTERNACIONAL BRASIL. Índice de percepção da corrupção 2019. Brasília: Transparência Internacional, 2020a. Disponível em: https://transparenciainternacional. org.br/ipc/?utm_source=tibr\&utm_medium=email\&utm_campaign=lancamento-ipc. Acesso em: 25 maio 2020 .

TRANSPARÊNCIA INTERNACIONAL BRASIL. Ranking de transparência em contratações emergenciais. Brasília: Transparência Internacional, 2020b. Disponível em: https://transparenciainternacional.org.br/ranking/. Acesso em: 04 jun. 2020.

UNITED NATIONS. The ten principles of the un global compact. Disponível em: https:// www.unglobalcompact.org/what-is-gc/mission/principles. Acesso em 10 jun. 2020.

VORSTER, Schalk W. Fighting corruption: a philosophical approch. In die skriflig/In luce verbi, South Africa, v. 47, n. 1, p. 1-7, jul. 2013. DOI: 10.4102/ids.v47i1.651.

WANIS, Rodrigo Otávio Mazieiro. A defesa da sociedade contra os atos de improbidade administrativa: análise crítica e desafios para a atuação eficiente do Ministério Público. Belo Horizonte: Editora D’Plácido, 2019.

WATANABE, Phillippe. OMS declara pandemia do novo coronavírus Sars-Cov-2. Folha de São Paulo, São Paulo, 11 mar. 2020. Disponível em: https:/www1.folha.uol.com.br/ equilibrioesaude/2020/03/oms-declara-pandemia-do-novo-coronavirus.shtml. Acesso em: 3 jun. 2020 . 
YAZIGI, Alejandro Ferreiro. La denuncia como factor de eficácia em el control de la corrupción. Revista de Ciência Política, Santiago, v. 18, n. 1-2, p. 105-114, 1996. Disponível em: https:// repositorio.uc.cl/bitstream/handle/11534/10862/000180053.pdf?sequence=1\&isAllowed=y. Acesso em 26 maio2020.

ZENKNER, Marcelo. O papel do setor privado na promoção da integridade nos negócios. In: PAULA, Marco Aurélio Borges de; CASTRO, Rodrigo Pironti Aguirre de (coord.). Compliance, gestão de riscos e combate à corrupção: integridade para o desenvolvimento. Belo Horizonte: Fórum, 2018. p. 135-166.

Como citar: SOUZA, Luciana Cristina; ALMEIDA, Fabiola Fonseca Fragas de. Controle de integridade de ações públicas durante a pandemia de COVID-19. Scientia Iuris, Londrina, v. 25, n. 1, p. 10-28, mar. 2021. DOI: 10.5433/21788189.2021v25n1p10. ISSN: 2178-8189.

Recebido em 17/06/20

Aprovado em 24/02/21 